\title{
DETECTION OF BRAF MUTATION IN MELANOMA FOUND IN TISSUE AND CFDNA BY USING A HIGHLY SENSITIVE PNA-CLAMP PCR.
}

\author{
REger R.Mikaeel ${ }^{*}$,ISAVella Evangelou, Joshua BILbIE, \\ JAMES HOWARD PRINGLE and GERALD SALDANHA ${ }^{* *}$ \\ *Dept. of Biology, College of Science, University of Duhok, Kurdistan Region-Iraq \\ *** Dept. of cancer Studies and Molecular Medicine, University of Leicester-England
}

(Received: November 2, 2017; Accepted for publication: December 28, 2017)

\begin{abstract}
Malignant melanoma results from ongoing activation of the mitogen activated protein kinases(MAPK ) pathway, commonly driven by mutations in BRAF. Several selective inhibitors of this pathway are used clinically, most notably the Vemurafenib and Dabrafenib. Different methods for BRAF mutation detection exist in the United Kingdom, including pyrosequencing, COBAS test and Sanger sequencing. However, there is significant variability in the analytical sensitivity of these tests. A highly sensitive PCR assay was developed to detect low tumor cell percentage of $0.1 \%$ in formalin fixed paraffin embedded (FFPE) tissue and plasma. The assay was developed on stable cell lines containing BRAF (codon 600) mutations. Peptide nucleic acid (PNA) Clamp PCR was used for the selective amplification of DNA target sequences. Total DNA was extracted from 48 FFPE tissues and 20 blood plasma (14 matched) stage II-IV melanoma patients and screened for BRAF mutations. Results were correlated with COBAS test data and clinical parameters. PNA Clamp PCR on FFPE tissue showed 46\% (n=22) BRAF mutants. Four more BRAF mutant cases were identified using PNA clamp methodology when compared to COBAS. Sample cases were independently tested. Matched samples showed $85 \%(n=12)$ correlation for BRAF mutation status $(6+v e, 4-v e, 2$ with no residual tumor burden). There were two cases which were positive for COBAS test and PNA Clamp PCR but negative for cfDNA. This demonstrates an innovative and highly sensitive technique for the detection of the common driver mutations in melanoma using exceptionally low tumor burden samples, representing a useful tool for future research and clinical application.
\end{abstract}

KEYWORDS: Melanoma, BRAF, Quantitative PCR, FFPE tissue, cfDNA

\section{INTRODUCTION}

$\mathbf{M}$ elanoma represents $4 \%$ of the common cancers (Cancer research uk. org, 2011), which counts as a significant disease burden worldwide and has major morbidity and mortality implications. The identification of common driver mutations in melanoma such as BRAF is the biggest step made in understanding melanoma so far. The RAF family comprises ARAF, BRAF and CRAF which are serine/threonine kinases. BRAF mutation is found in $43 \%$ of melanomas (Cancer. sanger. ac. uk, 2014). RAF is involved in MAPK pathway and in many cellular processes including cell proliferation, differentiation and transcriptional regulation. Mutations at codon 61 result in improved BRAF activity and increased phosphorylation of downstream targets. BRAF mutation in the majority of cases does not co-exist with any other mutation. BRAF is usually found in younger patients and have greater number of nevi. In comparison patients with chronic sun exposure were less likely to have BRAF mutations (Hacker et al., 2010). Vemurafenib and Dabrafenib inhibitors are reported to increase survival rate of melanoma patients. Vemurafenib was developed as a specific BRAF inhibitor for the V600E mutation. When patients are treated with BRAF inhibitors they show to have a temporary disease stabilisation and $15 \%$ of patients have a small progress at 6-8 weeks (Chapman P. et al., 2011). There are various methods for the detection of mutations in melanoma such as COBAS 4800 BRAF V600 test, Sanger sequencing, mutant allele-specific PCR, PNA clamp real-time PCR and pyrosequencing (Lyon E. et al., 2009). However, survival rates for BRAF inhibitors are poor and in relation to emerging resistance and how expensive the drugs are, new sensitive methods for detection 
of mutations and cost effective should be used. The need for a more sensitive and specific method for detecting mutations lead to the development and application of PNA Clamp PCR. According to Murdock et al., (2002), PNA Clamp PCR is a very sensitive method which can detect single nucleotide changes even if they exist in a small amount of the total DNA. As a result, where there is a wild- type and a mutant sequence, the wildtype can be blocked by the PNA and allow the amplification of mutant. PNA Clamp PCR can detect 1/20.000 alleles in some cases (Murdock D. et al., 2002). The high sensitivity of this method potentially will allow the detection of mutation in low frequency tumors and the treatment of more patients.

The cfDNA is the circulating free DNA present in the plasma or serum not only in cancer patients but also in healthy individuals. It is a double stranded molecule with molecular weight from 0.18-21 kB (Jahr S. et al., 2001, Stroun M. et al., 1987). However, the weight of cfDNA is significantly lower than genomic DNA (Jung K. et al., 2010). Research of cfDNA is poor due to nonspecific sensitive and analytical methods. Isolation procedures and sensitive PCR techniques with specific dyes have enabled progression in the research and now it is a potential diagnostic biomarker. In the past, detection of low concentration of cfDNA was not reliable (Kamm R. et al., 1972) in comparison to nowadays, with PCR assays and fluorescent dyes, cfDNA can be detected in healthy individuals as well. The aims and objectives of this project were to use a highly sensitive assay which can detect a low tumour cell percentage in BRAF by using cfDNA and FFPE tissues. PNA Clamp ASLNA qPCR was used for the selective amplification of DNA target sequences that differ by a single base pair. An assay for detecting BRAFV600E has already been developed and it was used to assess FFPE tissue samples and blood samples of melanoma patients to evaluate the frequency of BRAF mutations.

\section{MATERIALS AND METHODS}

\section{Cell lines}

Skin melanoma SK-MEL-28 and SK-MEL- 5 cell lines were used for this research. The two cell lines are malignant melanoma cell lines and were obtained from Dr. Pringle's lab (Reader in Molecular Pathology at University of Leicester) and cultured appropriately. SK-MEL-5 is derived from the skin and is heterozygous for BRAF p.V600E (c.1799T>A) and SK-MEL-28 is derived from the skin and is homozygous for BRAF
p.V600E (c.1799T>A) (Cancer.sanger.ac.uk, 2014).

\section{Melanoma samples}

A number of 48 FFPE tissue blocks and 20 blood plasma of melanoma patients (14 matched with tissue) collected from 2008-2014; were obtained from pathology archives at Leicester Royal Infirmary and were tested for BRAF V600E by PNA Clamp allele specific locked nucleic acid (ASLNA) quantitative PCR (qPCR) . All samples were taken from melanoma patients (2008-2014) and were tested for histological and clinic-pathological features. The clinicpathological features of the melanoma samples are shown in table 1. 
Table (1): Clinic-pathological features of melanoma cases

\begin{tabular}{ll}
\hline Gender & 35 \\
\hline Male & 19 \\
\hline Female & \\
\hline Age (median age 71 years) & 35 \\
\hline $\mathbf{5 7 1}$ years & 19 \\
\hline$>71$ years & \\
\hline & 33 \\
\hline Primary & 11 \\
\hline Secondary & 4 \\
\hline Unknown & \\
\hline & 22 \\
\hline Location & 11 \\
\hline Torso & 8 \\
\hline Limbs & 2 \\
\hline Head and neck & 1 \\
\hline Acral melanoma & 4 \\
\hline Mucosal melanoma & 32 \\
\hline Unknown & \\
\hline
\end{tabular}

\section{Braf Mutation Analysis}

\section{Cobas 4800 Braf V600 Mutation Test}

All FFPE tissue samples had been tested with COBAS 4800 BRAF V600 Mutation Test (Roche diagnostics), prior to quantitative PCR (qPCR) analysis. COBAS 4800 is able to detect BRAF V600 mutation in FFPE melanoma tissue. It is usually used in clinical trials to find the BRAF $^{\mathrm{V} 600 \mathrm{E}}$ status of the patients and help to decide which patients will receive BRAF inhibitor (vemurafenib) treatment. COBAS test is performed by using the DNA sample preparation kit according to the manufacturers' instructions.

Primer, Probe And Pna Design For Aslna Qpcr

$B R A F$ ASLNA primers, probe and PNA for qPCR were designed and provided by previous students (Tayeb B. and Ehdode A., 2013). The sequences of $B R A F$ primers, probes and PNA are listed in table 2.

The appropriate volume of sterile ultrapure (UP) water was added to the primer tubes to achieve concentration of $100 \mathrm{pmol} / \mu \mathrm{l}$. Then, aliquots of primers were made by diluting $5 \mu 1$ of the primer stock in $95 \mu \mathrm{l}$ of UP water $(1: 10$ dilution). Peptide nucleic acid (PNA) was diluted in the same manner as primers. Probe aliquots were made by diluting $2 \mu \mathrm{l}$ of probe in $98 \mu \mathrm{l}$ of UP water (1:50 dilution).

Table (2): ASLNAqPCR primers, probes and PNA for $B R A F^{V 600 E}$

\begin{tabular}{cc}
\hline $\begin{array}{c}\text { Forward primer } \\
+ \text { LNA }\end{array}$ & Wild type- TAGGTGATTTTGGTCTAGCTACAG+T \\
\cline { 2 - 2 } Reverse primer & Mutant- TAGGTGATTTTGGTCTAGCTACAG+A \\
\hline Probe & ATCCAGACAACTGTTCAAACTGATG \\
\hline PNA & Fam-AATCTCGATGGAGTGGGT-MGB \\
\hline
\end{tabular}




\section{Cell culture}

The cell lines that were cultured were SKMEL-28 and SK-MEL- 5. At first, cells were resuscitated from liquid nitrogen and defrosted at $37^{\circ} \mathrm{C}$ in water bath (Grand Instruments, Cambridge). The cells were transferred to a sterile falcon tube (Fisher Scientific, Loughborough, UK) containing $10 \mathrm{~mL}$ pre-warmed Roswell Park Memorial Institute - 1640 (RPMI-1640) (Lonza, Verviers, Belgium) with $10 \%$ foetal calf serum (FCS) (Sera-lab) and centrifuged (Scientific Laboratory Supplies) at $1000 \mathrm{rpm}$ for 5 minutes. Media was removed and the cell pellet was resuspended in pre-warmed RPMI-1640 media, transferred to a $25 \mathrm{~mL}$ dewar flask (T-25) (SigmaAldrich) in proportion 1:5, and incubated overnight $(\mathrm{o} / \mathrm{n})$ at $37^{\circ} \mathrm{C}$ in $5 \% \mathrm{CO} 2$ atmosphere. The following day growth media was removed and the cells monolayer was washed twice with pre-warmed $\left(37^{\circ} \mathrm{C}\right)$ phosphate buffered saline (PBS) (Lonza. Then, $5 \mathrm{~mL}$ of pre-warmed trypsin with Ethylenediaminetetraacetic acid (EDTA) solution were added on the cells. Cells were then centrifuged with an equal amount of growth medium (the growth medium neutralised the trypsin). Cell pellets were re-suspended in prewarmed growth media and allowed to grow until they reach $80-90 \%$ confluence.

For DNA extraction, the same procedure was followed but cells after re-suspension they were divided into $1.5 \mathrm{~mL}$ tubes and centrifuged at $14000 \mathrm{rpm}$ for 5 minutes. A pellet was formed and the growth media was discarded. Cell pellets were stored at $-80^{\circ} \mathrm{C}$ for DNA extraction.

\section{DNA extraction from cell lines}

DNA was extracted from SK-MEL-28 and SKMEL- 5 cell lines cell. Cell pellets of each cell line were re-suspended in $250 \mu \mathrm{l}$ of $0.05 \mathrm{M}$ Tris $\mathrm{pH}$ $8 / 0.1 \%$ SDS. Proteinase kinase (PK) was then added. After incubation an equal amount of phenol/chloroform/IAA was then added to the tube and centrifuged. The top layer (aqueous) of the solution was added to a clean $1.5 \mathrm{~mL}$ tube and an equal amount of phenol/chloroform/IAA (Sigma Aldrich) was added and centrifuged. The top layer was again transferred to a clean tube. Cold ethanol $\left(-20^{\circ} \mathrm{C}\right)$ and $1 \mathrm{M}$ sodium chloride $(\mathrm{NaCl})(1 / 10$ of starting volume; $2.5 \mu \mathrm{l})$ were added to the mixture and left at $-20^{\circ} \mathrm{C}$ for 30 minutes and microfuged at $4^{\mathrm{O}} \mathrm{C}$. Following, the pellet was washed with ethanol and centrifuged and the ethanol was left to air dry. Finally the pellet was re-suspended in ultrapure sterile water and stored at $4^{\circ} \mathrm{C}$.

\section{DNA extraction from FFPE tissue}

FFPE tissues were prepared and the DNA was extracted using the QIAamp DNA FFPE tissue kit (Qiagen, Hilden, Germany; cat.no: 56404). Slides were incubated at $65^{\circ} \mathrm{C}$ for 10 minutes and then they were de- waxed and rehydrated. ATL buffer were used to scrape the sections and $10 \mu \mathrm{l}$ of proteinase $\mathrm{K}$ recombinant were added and incubated. Then, $200 \mu \mathrm{l} \mathrm{AL}$ buffer were added in each tube, centrifuged and transferred safe-lock eppendorfs. Samples were heated and transferred to $1.5 \mathrm{~mL}$ tubes. $200 \mu \mathrm{l}$ of absolute ethanol were added and centrifuged. Samples were then applied on QIAamp columns and centrifuged. Columns were then re-placed in a new collection tube and $500 \mu \mathrm{l}$ buffer AW1 were added and centrifuged again as before. Then, $500 \mu 1$ of buffer AW2 were added and centrifuged. After that, $35 \mu \mathrm{l}$ buffer $\mathrm{AE}$ were added. Elution of DNA was transferred to a new tube and stored at $4^{\circ} \mathrm{C}$.

\section{cfDNA extraction from blood plasma}

Circulating cell-free (cfDNA) was extracted from blood plasma using QIAamp Circulating Nucleic acid kit (Qiagen, Hilden, Germany). Plasma samples $(1 \mathrm{~mL})$ were thawed and centrifuged and $100 \mu \mathrm{l}$ PK (Qiagen, Hilden, Germany) was added and $1 \mathrm{~mL}$ of plasma supernatant was added. $0.8 \mu \mathrm{l}$ of ACL buffer were added, vortex for 30 seconds and incubated at water bath.

An additional $1.8 \mu \mathrm{l}$ of ACB buffer were added, vortex for 30 seconds and incubated on ice. $680 \mu 1$ of the mixture were added to the QIAamp columns each time and centrifuged. Then, ACW1 buffer were added and centrifuged. The same procedure was repeated for buffer ACW2 $(700 \mu \mathrm{l})$ centrifuged at $14000 \mathrm{rpm}$ for 3 minutes and incubated. Then, $50 \mu \mathrm{l}$ of AVE buffer were applied and incubated at RT for 3 minutes and were centrifuged.

\section{Real time PCR}

Quantitative real-time polymerase chain reaction (qPCR) for BRAF gene was performed. ASLNAqPCR was completed by using $7 \mu \mathrm{l}$ of mastermix which included $5 \mu$ l of TaqMan Genotyping Master Mix (Applied Biosystems, cat.no: 4371355, Cheshire, UK), $0.2 \mu 1$ of appropriate forward primer, reverse primer, probe 
and PNA and the remaining amount of $\mu \mathrm{l}$ was used for sterile UP water. An additional $3 \mu l(10$ $\mathrm{ng} / 3 \mu \mathrm{l})$ of DNA was added to each well to give a final amount of $10 \mu \mathrm{l}$. The positive controls that were used for qPCR were human genomic DNA (HGD) and cell lines and for negative control no template control/sterile UP water (NTC) was used. $\Delta \mathrm{Ct}$ was collected from all samples after 50 cycles.

\section{$\mathbf{C t}$ and $\Delta \mathbf{C t}$}

The cycle threshold $(\mathrm{Ct})$ is the amount of cycles needed for the signal to be produced. If the amount of target nucleic acid, in our case DNA, is low the $\mathrm{Ct}$ value will be higher and vice versa. For a qPCR of 40 cycles the following rules define the amount of DNA in the samples. If:

a) Cts < 29: strong positive reactions, large amount of DNA in the sample

b) Cts of 30-37: are positive reactions, moderate amounts of DNA in the sample.

c) Cts of 38-40: are weak reactions, minimal amounts of DNA which can occur by contamination.

However, we used 50 cycles as we were using touchdown (TD) method that increases the number of cycles by 10-15.

\section{Statistical analysis}

Microsoft Excel (2013) and GraphPad Prism version 6 (GraphPad software, California, United States) software were used for statistical analysis.

\section{RESULTS}

In order to find the frequency of mutations in melanoma, Catalogue of Somatic Mutations in Cancer (COSMIC) was used. The location of mutations in BRAF in figure 1. 


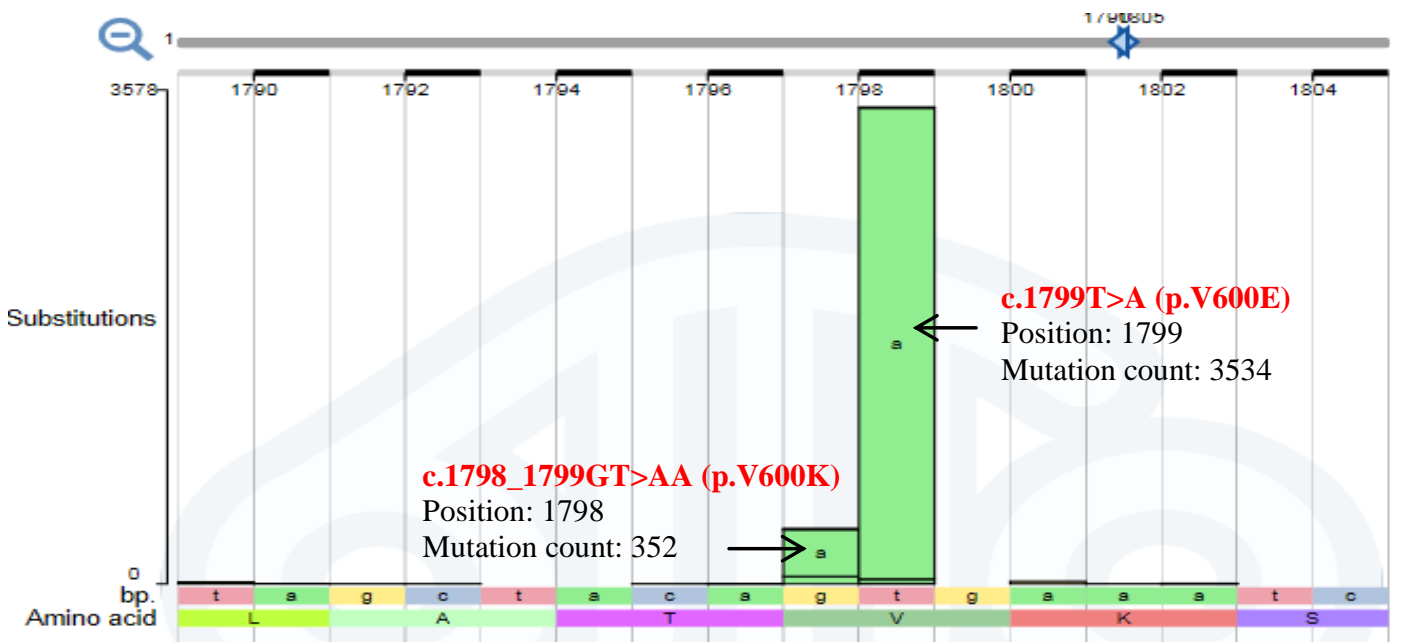

Fig (1):_Location of BRAF mutations according to COSMIC software. The most common mutation for BRAF appears to be at location c.1799 T>A (p.V600E).

The frequency of each mutation in malignant melanoma was found to be $43 \%$ for $B R A F$ mutations of which $\sim 90 \%$ of them was V600E.

\subsection{Specificity of BRAFV600 primers for PNA Clamp ASLNAqPCR \\ $B R A F^{V 600 E}$ LNA primers and PNA for} ASLNAqPCR were designed by previous students (Tayeb B. and Ehdode A., 2013). However, we checked the primers with HGDNA and cell lines (Figure 2). For HGDNA, wild-type LNA/-PNA had a Ct of 24 cycles, wild-type LNA/+PNA had a $\mathrm{Ct}$ of 32 cycles which gives a $\Delta \mathrm{Ct}$ of 8 cycles. The mutant LNA/ \pm PNA did not amplify. For SKMEL-5 mutant cell line, mutant LNA/ \pm PNA had a $\mathrm{Ct}$ of 24 cycles, wild-type LNA/-PNA 26 cycles and wild-type LNA/+PNA 35 cycles (Figure 2). 


\section{Analyses of clinical Samples}

The nature of the specimens varied. The $65 \%$ of the cases were men and the $35 \%$ women with median age of 71 years old; $65 \%$ of them were younger and $35 \%$ older than 71 years old.

\section{/3.7.1 BRAFV600E PNA Clamp ASLNAqPCR}

PNA Clamp ASLNAqPCR assay was used to detect BRAF ${ }^{\mathrm{V} 600 \mathrm{E}}$ mutation. For FFPE samples the $\triangle \mathrm{Ct}$ for SK-MEL-28 and SK-MEL-5 mutant cell lines was -3 and 0.5 cycles respectively. HGDNA had a $\Delta \mathrm{Ct}$ more than 20 cycles as there was no amplification, PNA completely supressed the wild-type. Negative control also did not amplify. With the wild-type primer HGDNA had a $\mathrm{Ct}$ of 28 cycles. Samples that amplified for BRAF ${ }^{\mathrm{V} 600 \mathrm{E}}$ were considered as mutated (Figure 3 A) and samples that did not amplify were considered as wild type (Figure 3 B). 

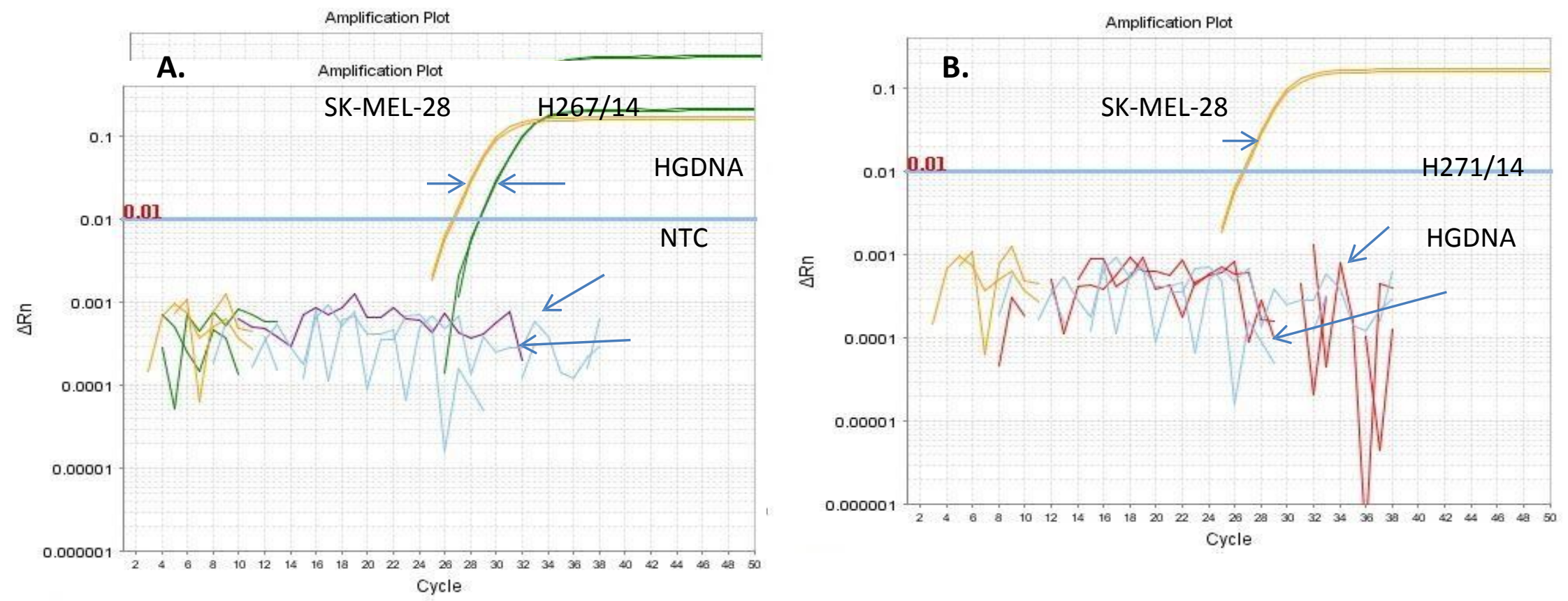

Fig. 3: Amplification plots of FFPE samples using PNA Clamp ASLNAqPCR. A) Representation of the melanoma cell line SK- MEL-28 amplification (orange) with a $\Delta \mathrm{Ct}$ of 27 cycles and a mutated for BRAF ${ }^{\mathrm{V} 600 \mathrm{E}}$ sample H267/14 (green) with a $\Delta \mathrm{Ct}$ of 29 cycles. HGDNA (blue) did not amplify along with the NTC (purple). B) Representation of the melanoma cell line SK-MEL-28 amplification (orange) with a $\Delta$ Ct of 27 cycles and a wild -type for BRAF $600 E$ sample H271/14 (red). HGDNA (blue) did not amplify along with the NTC (purple). 
For cfDNA samples the $\Delta \mathrm{Ct}$ for SK-MEL-28 and SK-MEL-5 mutant cell lines was -4 and 0.3 cycles respectively. HGDNA had a $\triangle \mathrm{Ct}$ more than 20 cycles as there was no amplification, PNA completely supressed the wild-type. Negative control also did not amplify. With the wild-type primer HGDNA had a Ct of 23 cycles. Samples that amplified for $\mathrm{BRAF}^{\mathrm{V} 600 \mathrm{E}}$ were considered as mutated (Figure 4A) and samples

that did not amplify were considered as wild
type
(Figure
4B). 


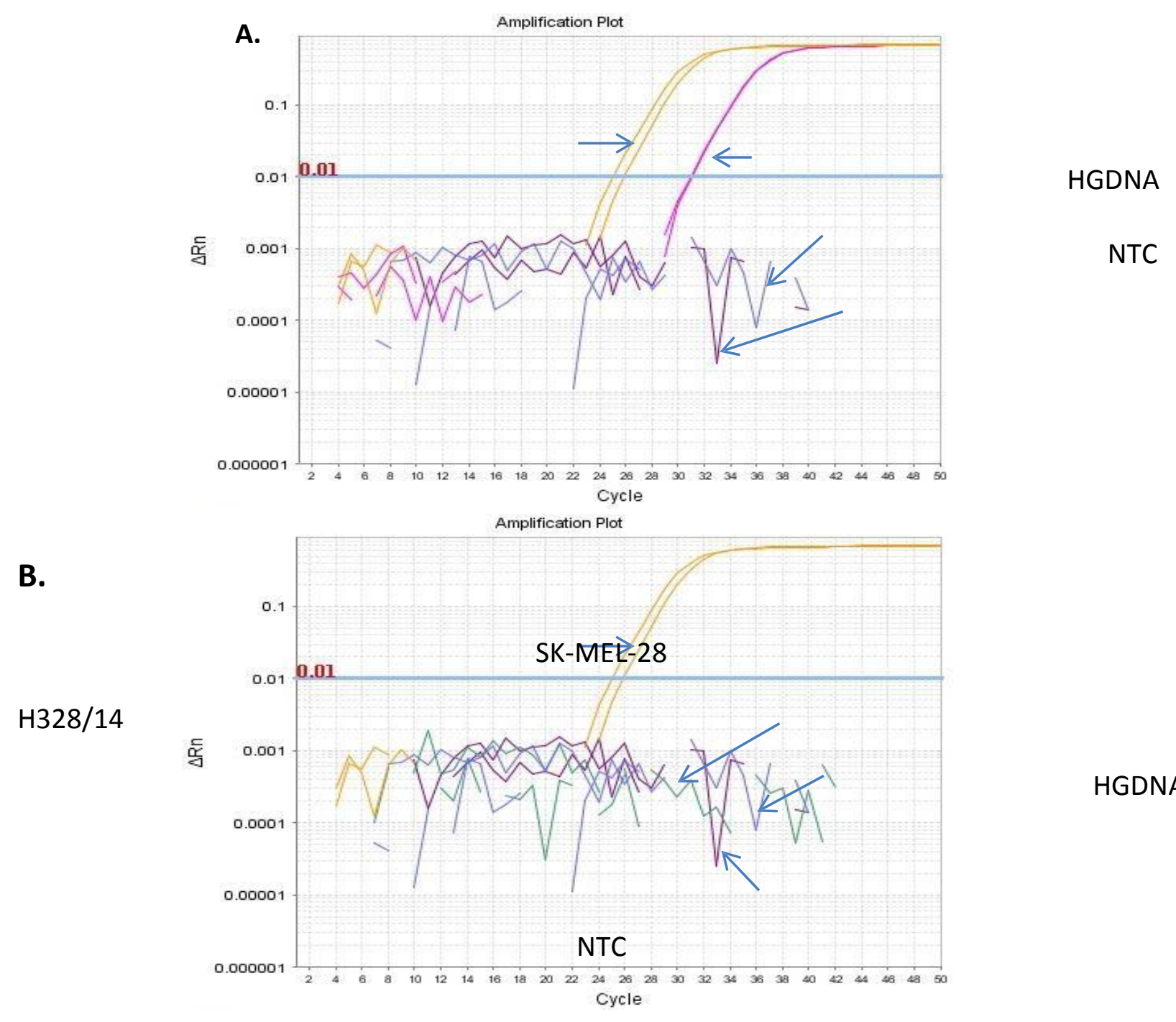

Fig. 4: Amplification plots of cfDNA samples using QUASAqPCR. A) Representation of the melanoma cell line SK-MEL-28 amplification (orange) with a $\triangle \mathrm{Ct}$ of 26 cycles and a mutated for BRAF ${ }^{\mathrm{V} 600 \mathrm{E}}$ sample H631/13 (pink) with a $\triangle \mathrm{Ct}$ of 31 cycles. HGDNA (blue) did not amplify along with the NTC (purple). B) Representation of the melanoma cell line SK-MEL-28 amplification (orange) with a $\Delta \mathrm{Ct}$ of 26 cycles and a wild -type for BRAF $\mathrm{V} 600 \mathrm{E}$ sample H328/14 (green). HGDNA (blue) did not amplify along with the NTC (purple). 
The status of the cases was confirmed by plotting the $\Delta \mathrm{Ct}$ (y axis) against the wild-type

$\mathrm{Ct}$ (x axis). Cases with undetermined mutant $\mathrm{Ct}$ were given a mutant $\mathrm{Ct}$ mean value of 50 cycles in order to calculate the $\Delta \mathrm{Ct}$. Negative samples for BRAF $^{\mathrm{V} 600 \mathrm{E}}$ had a $\Delta \mathrm{Ct}>10$ cycles. A "'cut off" line was drawn to represent the detectable amount of DNA and determine the status of samples that had single amplification. The line started approximately 10 cycles after the cell line amplification cycle and was parallel to the line formed by samples that appeared to be wild-type. Samples below the line were considered as mutated for the BRAFV600E mutation and samples above the line considered as wild-type tumours for BRAF ${ }^{\mathrm{V} 600 \mathrm{E}}$. Samples very close to the "cut-off'" line were considered as wild-type. PNA Clamp ASLNAqPCR detected BRAF V600E in 22 out of 48 corresponding to $46 \%$ of the samples (Figure 5 A). 21 out of 22 mutated FFPE samples amplified in duplicate (pink) and 1 had single amplification (turquoise). The information for mutated FFPE samples is shown in table (5) and extended information in the appendix. cfDNA samples were also tested for the BRAF ${ }^{\mathrm{V} 600 \mathrm{E}}$ mutation. PNA Clamp ASLNAqPCR detected BRAF $^{\mathrm{V} 600 \mathrm{E}}$ in 8 out of 20 corresponding to $40 \%$ of the samples (Figure $5 \mathrm{~B}$ ). 6 out of 8 mutated cfDNA samples amplified in duplicate and 2 had single amplification. The information for mutated cfDNA samples is shown in table (6) and extended information in the appendix. For six of the cfDNA samples matched tissue wasn't available and two of them were mutated for BRAF $^{\mathrm{V} 600 \mathrm{E}} .10$ of the remaining 14 matched samples were mutated for BRAF ${ }^{\mathrm{V} 600 \mathrm{E}}$ on FFPE tissue and 6 of them mutated for BRAF ${ }^{\mathrm{V} 600 \mathrm{E}}$ on cfDNA. 
Journal of University of Duhok, Vol. 20, No.1 (Pure and Eng. Sciences), Pp 119-141, 2017

DOI: https://doi.org/10.26682/sjuod.2018.20.1.12

Table (5): Mutated FFPE samples for BRAF ${ }^{\mathrm{V} 600 \mathrm{E}}$ PNA Clamp ASLNAqPCR

\begin{tabular}{|c|c|c|c|}
\hline FFPE Block no & WT Ct & MUT Ct & $\Delta \mathrm{Ct}$ \\
\hline$H 244 / 14$ & 27.529 & 28.332 & 0.803 \\
\hline $\mathrm{H} 245 / 14$ & 36.21 & 37.24 & 1.03 \\
\hline $\mathrm{H} 247 / 14$ & 33.249 & 36.52 & 3.271 \\
\hline $\mathrm{H} 252 / 14$ & 29.974 & 27.817 & -2.156 \\
\hline $\mathrm{H} 255 / 14$ & 33.174 & 31.739 & -1.435 \\
\hline $\mathrm{H} 257 / 14$ & 34.346 & 34.087 & -0.259 \\
\hline H258/14 & 33.317 & 33.937 & 0.62 \\
\hline $\mathrm{H} 263 / 14$ & 33.662 & 29.338 & -4.324 \\
\hline $\mathrm{H} 264 / 14$ & 30.979 & 28.426 & -2.553 \\
\hline H267/14 & 28.256 & 29.803 & 1.547 \\
\hline H269/14 & 28.816 & 31.418 & 2.602 \\
\hline $\mathrm{H} 272 / 14$ & 24.812 & 32.62 & 7.808 \\
\hline $\mathrm{H} 274 / 14$ & 29.363 & 36.192 & 6.829 \\
\hline $\mathrm{H} 275 / 14$ & 25.479 & 26.78 & 1.301 \\
\hline $\mathrm{H} 278 / 14$ & 29.729 & 32.659 & 2.93 \\
\hline H398/14 & 29.906 & 31.785 & 1.878 \\
\hline H399/14 & 30.545 & 31.071 & 0.526 \\
\hline $\mathrm{H} 403 / 14$ & 27.968 & 35.486 & 7.518 \\
\hline $\mathrm{H} 404 / 14$ & 28.067 & 28.825 & 0.758 \\
\hline H406/14 & 26.742 & 31.822 & 5.08 \\
\hline $\mathrm{H} 407 / 14$ & 29.473 & 30.756 & 1.284 \\
\hline H409/14 & 26.938 & 33.889 & 6.951 \\
\hline
\end{tabular}

Table (6): Mutated cfDNA samples for BRAF ${ }^{\mathrm{V} 600 \mathrm{E}}$ PNA Clamp ASLNAqPCR

\begin{tabular}{cllll}
\hline cfDNA no & Matched FFPE & WT Ct & MUT Ct & $\Delta$ Ct \\
\hline H573/13 & H244/14 & 29.613 & 31.523 & 1.909 \\
\hline H631/13 & H272/14 & 29.234 & 32.457 & 3.223 \\
\hline
\end{tabular}


Journal of University of Duhok, Vol. 20, No.1 (Pure and Eng. Sciences), Pp 119-141, 2017 DOI: https://doi.org/10.26682/sjuod.2018.20.1.12

\begin{tabular}{|c|c|c|c|c|c|}
\hline \multicolumn{2}{|r|}{ H337/14 } & $\mathrm{H} 399 / 14$ & 28.254 & 34.607 & 6.352 \\
\hline \multicolumn{2}{|r|}{$\mathrm{H} 492 / 13$} & $\mathrm{H} 404 / 14$ & 28.368 & 33.798 & $\begin{array}{c}5.4 \\
3\end{array}$ \\
\hline \multirow[t]{2}{*}{132} & $707 / 12$ & $\mathrm{H} 407 / 14$ & 27.362 & 26.208 & -1.154 \\
\hline & H348/14 & $\mathrm{H} 409 / 14$ & 28.915 & 37.299 & 8.384 \\
\hline & H391/14 & - & 28.611 & 32.661 & $\begin{array}{c}4.0 \\
5 \\
\end{array}$ \\
\hline & H392/14 & - & 26.841 & 27.43 & 0.589 \\
\hline
\end{tabular}

Comparison of COBAS 4800 BRAF V600 mutation test and PNA Clamp PCR for FFPE tissue samples

COBAS 4800 test and PNA Clamp PCR were used on FPPE tissue samples to identify the BRAFV600 status of the samples. By comparing these methods, it was found that $40 \%$ of the samples $(n=19)$ were mutated for both methods, $0 \%$ were wild-type with PNA Clamp PCR and mutated with COBAS 4800 test, $8 \%(n=4)$ were mutated for PNA Clamp PCR but wild-type for COBAS 4800 test and $52 \%(n=25)$ were wild-type for both methods (Table 7). According to this comparison, the COBAS test was $100 \%$ sensitive, $86 \%$ specific and $92 \%$ accurate. 
Table 7: Comparison of COBAS 4800 BRAF V600 mutation test and PNA Clamp PCR for FFPE tissue samples.

\begin{tabular}{lll}
\hline PNA Clamp PCR & BRAF $^{V 600 E}$ mutated & BRAF $^{V 600 E}$ wild-type \\
\hline COBAS 4800 & & 0 \\
\hline$B R A F^{V 600 E}$ mutated & 19 & 25 \\
\hline
\end{tabular}

$$
\begin{gathered}
\text { Sensitivity }=\frac{q P C R / C O B A S+v e}{(q P C R / C O B A S+v e)+(q P C R-v e / C O B A S+v e)}=\frac{19}{19}=1=\mathbf{1 0 0} \% \\
\text { Specificity }=\frac{q \mathrm{qPCR}-\mathrm{ve} / \mathrm{COBAS}-\mathrm{ve}}{(\mathrm{qPCR}-\mathrm{ve} / \mathrm{COBAS}-\mathrm{ve})+(\mathrm{qPCR}+\mathrm{ve} / \mathrm{COBAS}-\mathrm{ve})}=\frac{25}{29}=0.86=\mathbf{8 6} \% \\
\text { Accuracy }=\frac{\left(\frac{\mathrm{qPCR}}{\mathrm{COBAS}}+\mathrm{ve}\right)+\left(\mathrm{qPCR}-\frac{\mathrm{ve}}{\mathrm{COBAS}}-\mathrm{ve}\right)}{\text { Total number of cases }}=\frac{44}{48}=0.916=\mathbf{9 2} \%
\end{gathered}
$$

\subsection{Patients stage and concentration of cfDNA}

The concentration of cfNDA varied from $0.003-0.533 \mathrm{ng} / 3 \mu \mathrm{L}$. The patients' stage ranged from stage II-IV; fifteen samples were stage IV, two stage III, one stage II and two patients that had tumour excision. The information for the stage and cfDNA concentration of each samples in shown in figure 6 . 
BRAF V600E cfDNA concentration according to patients stage

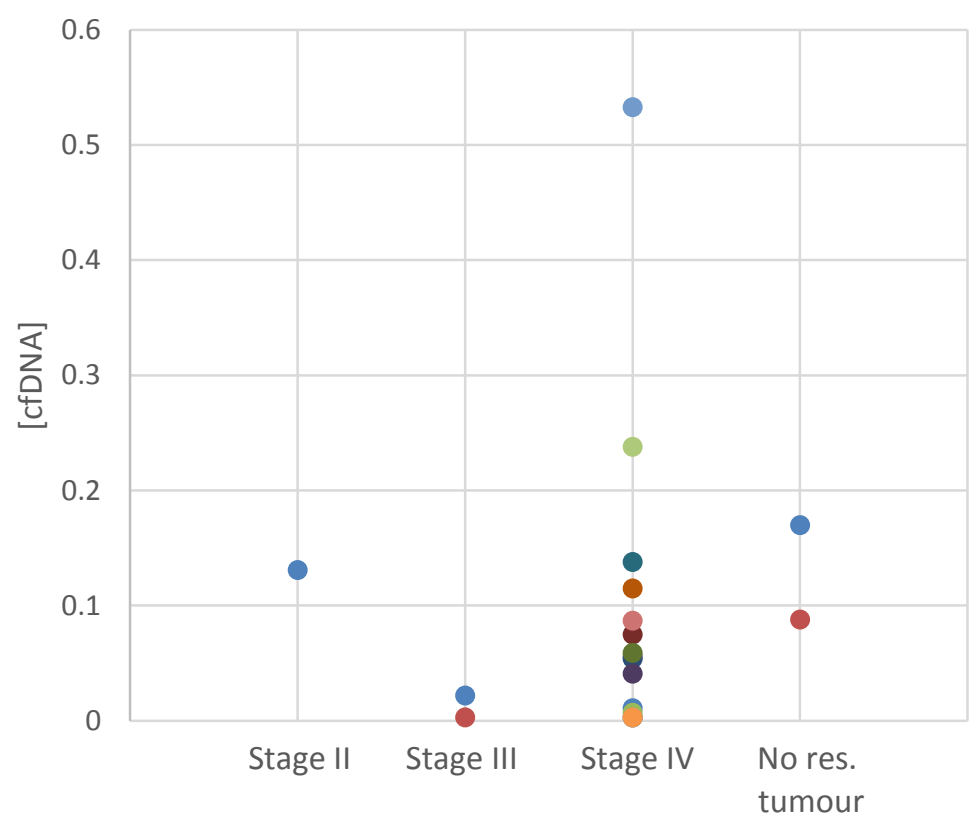

Fig. (6): Patient's stage and concentration of cfDNA

\subsection{Information on clinical samples}

A number of 14 cfDNA samples were available that matched FFPE tissue that were

already analysed with qPCR (6 BRAF FFPE and cfDNA +v and $4 B R A F$ FFPE +ve). Information for the cases is shown in table 8 . 
Table (8): Matched FFPE tissue with cfDNA samples

\begin{tabular}{|c|c|c|c|c|c|}
\hline $\begin{array}{l}\text { FFPE Block } \\
\text { no. }\end{array}$ & cfDNA no. & COBAS & FFPE Tissue & cfDNA* & Comments \\
\hline & & & BRAF & BRAF & \\
\hline $\mathrm{H} 242 / 14$ & $\mathrm{H} 347 / 14$ & Negative & -ve & -ve & $! !$ \\
\hline H244/14 & $\mathrm{H} 573 / 13$ & Positive & $+v e$ & $+v e$ & - \\
\hline H249/14 & $\mathrm{H} 493 / 14$ & Negative & -ve & -ve & !! \\
\hline $\mathrm{H} 251 / 14$ & $\mathrm{H} 668 / 13$ & Negative & -ve & -ve & !! \\
\hline H272/14 & $\mathrm{H} 631 / 13$ & Positive & $+v e$ & $+v e$ & - \\
\hline $\mathrm{H} 275 / 14$ & $\mathrm{H} 327 / 14$ & Positive & $+v e$ & -ve & $\begin{array}{c}\text { Previous metastatic disease, but all } \\
\text { metastases excised. No residual tumour. }\end{array}$ \\
\hline H398/14 & $\mathrm{H} 338 / 14$ & Positive & $+v e$ & -ve & Previous BRAF inhibitor \\
\hline H399/14 & H337/14 & Positive & $+v e$ & $+v e$ & $\begin{array}{l}\text { Previous BRAF inhibitor stopped due to } \\
\text { toxicity }\end{array}$ \\
\hline $\mathrm{H} 400 / 14$ & $\mathrm{H} 378 / 14$ & Negative & -ve & -ve & !! \\
\hline $\mathrm{H} 403 / 14$ & $\mathrm{H} 1436 / 14$ & Positive & $+v e$ & -ve & no information about treatment \\
\hline H404/14 & $\mathrm{H} 492 / 13$ & Positive & $+v e$ & $+v e$ & BRAF inhibitor after blood taken \\
\hline $\mathrm{H} 406 / 14$ & $\mathrm{H} 669 / 14$ & Positive & $+v e$ & -ve & $\begin{array}{l}\text { Previous metastatic disease, but all } \\
\text { metastases excised. No residual tumour. }\end{array}$ \\
\hline $\mathrm{H} 407 / 14$ & $\mathrm{H} 1707 / 14$ & Positive & $+v e$ & $+v e$ & $! !$ \\
\hline H409/14 & $\mathrm{H} 348 / 14$ & Positive & +ve & +ve & !! \\
\hline
\end{tabular}

*FFPE tissue and cfDNA taken at different time points. !!: metastatic disease but no treatment (if BRAF +ve) but may have had treatment (if BRAF -ve but obviously not a BRAFi e.g. dacarbazine or ipilumimab)

\section{DISCUSSION}

Testing of tumor tissue remains the recommended method for detecting the presence of somatic mutations in human malignancies. Melanoma is one of the most aggressive forms of cancers and targeted therapy for driver mutations like BRAF is essential (Molina et al., 2015). BRAF mutation is found in $43 \%$ of melanomas (Cancer.sanger.ac.uk, 2014 ) and $\sim 90 \%$ of these are thymine to adenine substitutions at codon 600 valine to glutamine at position c.1799T >A (V600E). Therefore, V600E is considered to be the most frequent somatic point mutation in metastatic melanoma, providing a unique molecular marker for this malignancy (Lovly et al., 2012 and Rubinstein et al., 2010). In this project we evaluated whether the frequency of detected BRAFV60gE mutations in melanoma and whether cfDNA can be used as a prognostic factor for melanoma patients. For this reason, a BRAFV600E mutation detection assay was developed based on Real time PCR and specifically the technique applied was PNA Clamp ASLNA qPCR. Results were compared with COBAS 4800 BRAFV600E mutation test, which is the only test approved for selection of patients for treatment with BRAF inhibitors based on positive mutation test.

ASLNAqPCR use primers with an extra LNA base on their 3'-end. An ASLNA assay is cost effective, very sensitive and specific and also gives information about the ratio of wild-type and mutant alleles (Morandi L. et al., 2012). In our study, LNA was used to increase PCR sensitivity. LNA's have been proved to be useful for mutation detection with high sensitivity for KRAS and BRAF (Arcila M. et al., 2011). All the samples were analysed by PNA Clamp ASLNAqPCR and the status of each sample was determined by the amplification of each sample. Samples were determined as mutant when tested with mutant primer and there was amplification in duplicate. If there was no amplification samples were considered as wild type, negative for 
BRAFV600E mutation. For some of the samples the status was not clear as there was single amplification. In order to overcome this problem the status of the cases was confirmed by plotting the wild-type $\mathrm{Ct}$ (x axis) against the $\Delta \mathrm{Ct}$ (y axis). Cases with undetermined mutant $\mathrm{Ct}$ were given a mean value of 50 cycles in order to calculate the $\Delta$ Ct. Negative samples for BRAFV600E had a $\Delta \mathrm{Ct}>10$ cycles. A "cut off" line, the slope, showing the single genome amplification, defining the theoretical limits for detecting mutant alleles (1.6 molecules) was drawn to represent the detectable amount of DNA and determine the status of samples that had single amplification. The line started approximately 10 cycles after the cell line amplification cycle and was parallel to the line formed by samples that appeared to be wild-type for BRAFV600E. Samples below the line were considered as mutated for the BRAFV600E mutation and samples above the line considered as wild-type tumours for BRAFV600E. Samples very close to the "cut-off" line were considered as wild-type. In a study of 193 patients, $48 \%$ of the cases harbour BRAF mutations of which $71 \%$ were V600E (Carlino M. et al., 2014). In comparison Sclafani et al. (2013), found that BRAF mutations in melanoma are up to $66 \%$ in exons 11 and 15 but the majority of the mutations were at position $1799 \mathrm{~T}>\mathrm{A}$ and only few belong to exon 11 (Sclafani F. et al., 2013). The research in melanoma has been improved by the advances in BRAF inhibitors. The use of the BRAF inhibitors to treat patients that hold BRAFV600E mutation results to the reduction of advanced lesions (Weeraratna A., 2012). The first response to vemurafenib is very impressive with success rate of $\approx 50 \%$ and also increased survival however, resistance to the inhibitor starts after 218 months after the first treatment (Cox A. et al., 2012). Moreover, secondary tumours may occur from the BRAF inhibition such as cutaneous squamous-cell carcinomas and keratoacanthomas (Weeraratna A., 2012). In addition by comparing the COBAS 4800 BRAFV600E test with PNA Clamp ASLNAqPCR on FFPE tissue samples, results show that the biological sensitivity of the assay was $100 \%$ as all the samples that were BRAF mutated with COBAS test were also mutated for PNA Clamp ASLNAqPCR. The biological specificity was $86 \%$ and the accuracy was $92 \%$. These results suggest that PNA Clamp ASLNAqPCR assay was more sensitive than the COBAS 4800 test as it detected four positive samples that were not detected with the COBAS test. The use of FFPE tissue from biopsies is essential for immunohistochemistry and haematoxylin and eosin staining but has several arising issues when is used with molecular methods such as qPCR. First of all, cross-linking is caused by formaldehyde which covalently links nucleic acids resulting is lower efficiency of molecules in qPCR (Perkel, 2014). Moreover, in cancer patients when the position of the tumour is difficult to perform biopsy, for example in lung cancer patients, the tumour material is inadequate (Sequist L. et al., 2009). In addition, the amount of tumour in FFPE tissue is low as it is mixed with normal tissue (Plesec T. et al., 2009). According to Fleischhacker et al. (2008) and Gerlinger et al., (2012), biopsies are taken from a part of the tumour arising the issue if all the mutant clones are included in tumour heterogeneity; leading to the conclusion that the specificity and sensitivity of qPCR is greatly affected as there are chemical changes in DNA and low number of molecules, resulting in higher $\mathrm{Ct}$ signalling Fleischhacker et al. (2008) and Gerlinger et al., (2012). On the other hand, cfDNA in qPCR might be a better biomarker as it is not formalin fixed and less nonspecific binding should be observed resulting in an increase of the sensitivity and the specificity (Aung K. et al., 2014).

According to a study by Board et al. (2008), cfDNA can be extracted by both plasma and serum with serum having the disadvantage of white blood cells (Board R. et al., 2008). In our study, BRAFV600E ASLNAqPCR assay showed a mutant ratio of 1:1000 mutant to wild type DNA. Fourteen cases that had matched tissue available were tested in both FFPE tissue and cfDNA in two different time points; FFPE tissue was tested first and then blood sample was taken at later time. Six of the cases were BRAF positive in both FFPE and cfDNA, four cases were BRAF positive only in FFPE tissue, one case was NRAS Q61R positive in FFPE tissue and three cases were negative. There is an explanation for mutation status in FFPE tissue and cfDNA samples. For the samples that were BRAFV600E positive for both FFPE and cfDNA, three had metastatic disease but did not receive treatment (H492/13 / H404/14, H1707/14 /H407/14 and $\mathrm{H} 348 / 14$ / H409/14), one was treated BRAF inhibitor but the treatment stopped due to toxicity (H399/14 / H337/14) and for two of the cases no clinical information for any treatment was given 
(H244/14 / H573/13 andH272/14 / H631/13). For the four cases that were BRAFV600E positive in FFPE tissue analysis, for two of them tumour was excised (no residual tumour) (H275/14 / H327/14 and H406/14 / H669/14), one was treated with BRAF inhibitor (H398/14 / H335/14) and for one no information was available (H403/14 /H1436/14). One case was positive for NRAS Q61R on FFPE tissue analysis and three other cases were negative for BRAFV600E which had treatment with non BRAF inhibitor (e.g dacarbazine or iptumimab). As a result it could be argued that the sensitivity of ASLNAqPCR and QUASAqPCR methods to detect mutation can be $100 \%$.

The use of cfDNA mutation testing could be used as an initial screening step to determine the patients with BRAF mutant tumours for clinical trials which will be very beneficial as more patients with metastatic disease will be identified earlier which will therefore improve efficiency of future clinical trials. In addition this method will be very useful in cases where biopsy is difficult to be performed.

\section{REFERENCES}

- Arcila, M., Lau, C., Nafa, K. and Ladanyi, M. (2011). Detection of KRAS and BRAF Mutations in Colorectal Carcinoma: Roles for HighSensitivity Locked Nucleic Acid-PCR Sequencing and Broad-Spectrum Mass Spectrometry Genotyping. The Journal of Molecular Diagnostics, 13(1), pp.64-73.

- Aung, K., Donald, E., Ellison, G., Bujac, S., Fletcher, L., Cantarini, M. et al , (2014). Analytical Validation of BRAF Mutation Testing from Circulating Free DNA Using the Amplification Refractory Mutation Testing System. The Journal of Molecular Diagnostics, 16(3), pp.343-349.

- Board, R., Williams, V., Knight, L., Shaw, J., Greystoke, A., Ranson, M., Dive, C., Blackhall, F. and Hughes, A. (2008). Isolation and extraction of circulating tumor DNA from patients with small cell lung cancer. Annals of the New York Academy of Sciences, 1137(1), pp.98-107.

- Cancer.org, (2014). What are the survival rates for melanoma skin cancer by stage?. [online] Available http://www.cancer.org/cancer/skincancermelanoma/detailedguide/melanoma-skin-cancersurvival-rates [Accessed 16 Jul. 2014].
- Cancer.sanger.ac.uk, (2014). COSMIC: Tissue browser. [online] Available at: http://cancer.sanger.ac.uk/cosmic/browse/tissue \#sn=skin\&ss=all\&hn=malignant_melanoma\&sh $=$ all\&in=t\&src=tissue [Accessed 31 May. 2014].

- Cancerresearchuk.org, (2014). Melanoma skin cancer: Cancer Research UK : CancerHelp UK. [online] Available at: http://www.cancerresearchuk.org/cancerhelp/type/melanoma/ [Accessed 4 April. 2014].

- Carlino, M., Haydu, L., Kakavand, H., Menzies, A., Hamilton, A., Yu, B., et al (2014). Correlation of BRAF and NRAS mutation status with outcome, site of distant metastasis and response to chemotherapy in metastatic melanoma. British journal of cancer, 111(2), pp.292-299.

- Chapman, P., Hauschild, A., Robert, C., Haanen, J., Ascierto, P., Larkin, J., et al (2011). Improved survival with vemurafenib in melanoma with BRAF V600E mutation. New England Journal of Medicine, 364(26), pp.2507-2516.

- Cox, A. and Der, C. (2012). The RAF inhibitor paradox revisited. Cancer cell, 21(2), pp.147149.

- Crowley, E., Di Nicolantonio, F., Loupakis, F. and Bardelli, A. (2013). Liquid biopsy: monitoring cancer-genetics in the blood. Nature Reviews Clinical Oncology, 10(8), pp.472-484.

- Fleischhacker, M. and Schmidt, B. (2008). Cell-free DNA resuscitated for tumor testing. Nature medicine, 14(9), pp.914-915.

- Gerlinger, M., Rowan, A., Horswell, S., Larkin, J., Endesfelder, D., Gronroos, E., et al (2012). Intratumor heterogeneity and branched evolution revealed by multiregion sequencing. New England Journal of Medicine, 366(10), pp.883-892.

- Hacker, E., Hayward, N., Dumenil, T., James, M. and Whiteman, D. (2010). The association between MC1R genotype and BRAF mutation status in cutaneous melanoma: findings from an Australian population.Journal of Investigative Dermatology, 130(1), pp.241-248.

- Jahr, S., Hentze, H., Englisch, S., Hardt, D., Fackelmayer, F., Hesch, R., et al (2001). DNA fragments in the blood plasma of cancer patients: quantitations and evidence for their origin from apoptotic and necrotic cells. Cancer research, 61(4), pp.1659-1665.

- Kamm, R. and Smith, A. (1972). Nucleic acid concentrations in normal human plasma. Clinical chemistry, 18(6), pp.519-522.

- Lyon, E. and Wittwer, C. (2009). LightCycler technology in molecular diagnostics. The 
Journal of Molecular Diagnostics, 11(2), pp.93101.

- Molina-Vila, M.A., de-las-Casas, C.M., BertranAlamillo, J., Jordana-Ariza, N., et al, 2015. cfDNA analysis from blood in melanoma. Annals of translational medicine, 3(20).

- Murdock, D. and Wallace, D. (2002). PNA-mediated PCR clamping. Springer, pp.145-164.

- Perkel, J. (2014). Working with FFPE Tissue | Biocompare Editorial Article. [online] Biocompare.com. Available at: http://www.biocompare.com/EditorialArticles/41751-Working-with-FFPE-Tissue/ [Accessed 27 Jul. 2014].

- Plesec, T. and Hunt, J. (2009). KRAS mutation testing in colorectal cancer. Advances in anatomic pathology, 16(4), pp.196-203.

- Rubinstein, J., Sznol, M., Pavlick, A., Ariyan, S., Cheng, E., Bacchiocchi, A., et al (2010). Incidence of the $\mathrm{V} 600 \mathrm{~K}$ mutation among melanoma patients with BRAF mutations, and potential therapeutic response to the specific BRAF inhibitor PLX4032. J Transl Med, 8(67), pp.10-1186.

- Sequist, L., Engelman, J. and Lynch, T. (2009). Toward noninvasive genomic screening of lung cancer patients.Journal of Clinical Oncology, 27(16), pp.2589-2591.

- Stroun, M., Anker, P., Lyautey, J., Lederrey, C. and Maurice, P. (1987). Isolation and characterization of DNA from the plasma of cancer patients. European Journal of Cancer and Clinical Oncology, 23(6), pp.707-712.

- Weeraratna, A. (2012). RAF around the edges-the paradox of BRAF inhibitors. $N$ Engl $\mathrm{J} \mathrm{Med,}$ 366(3), pp.271-3. 


\section{APPENDIX}

Table (9): $B R A F$ codon 600 V600E c.1799 T>A PNA Clamp ASLNAqPCR information for FFPE samples.

\begin{tabular}{|c|c|c|c|c|}
\hline Sample & WT Ct Mean & MUT Ct Mean & $\Delta \mathrm{Ct}$ & Status \\
\hline $\mathrm{H} 238 / 14$ & 41.499 & 46.740 & 5.241 & 1 \\
\hline $\mathrm{H} 239 / 14$ & 35.546 & 37.967 & 2.421 & 1 \\
\hline $\mathrm{H} 240 / 14$ & 38.304 & 50 & 11.696 & \\
\hline $\mathrm{H} 241 / 14$ & 36.818 & 50 & 13.182 & \\
\hline $\mathrm{H} 242 / 14$ & 27.242 & 50 & 22.758 & \\
\hline $\mathrm{H} 243 / 14$ & 34.403 & 50 & 15.597 & \\
\hline $\mathrm{H} 244 / 14$ & 27.529 & 28.332 & 0.803 & 2 \\
\hline $\mathrm{H} 245 / 14$ & 36.210 & 37.240 & 1.030 & 2 \\
\hline $\mathrm{H} 246 / 14$ & 37.194 & 50 & 12.806 & \\
\hline $\mathrm{H} 247 / 14$ & 33.249 & 36.520 & 3.271 & 2 \\
\hline $\mathrm{H} 248 / 14$ & 36.294 & 50 & 13.706 & \\
\hline $\mathrm{H} 249 / 14$ & 27.129 & 50 & 22.871 & \\
\hline $\mathrm{H} 250 / 14$ & 32.567 & 50 & 17.433 & \\
\hline $\mathrm{H} 251 / 14$ & 26.747 & 50 & 23.253 & \\
\hline $\mathrm{H} 252 / 14$ & 29.974 & 27.817 & -2.156 & 2 \\
\hline $\mathrm{H} 253 / 14$ & 32.348 & 50 & 17.652 & \\
\hline $\mathrm{H} 254 / 14$ & 32.073 & 50 & 17.927 & \\
\hline $\mathrm{H} 255 / 14$ & 33.174 & 31.739 & -1.435 & 2 \\
\hline $\mathrm{H} 256 / 14$ & 32.486 & 50 & 17.514 & \\
\hline $\mathrm{H} 257 / 14$ & 34.346 & 34.087 & -0.259 & 2 \\
\hline $\mathrm{H} 258 / 14$ & 33.317 & 33.937 & 0.620 & 2 \\
\hline $\mathrm{H} 259 / 14$ & 33.605 & 41.547 & 7.942 & 1 \\
\hline $\mathrm{H} 260 / 14$ & 31.527 & 50 & 18.473 & \\
\hline $\mathrm{H} 261 / 14$ & 33.117 & 50 & 16.883 & \\
\hline $\mathrm{H} 262 / 14$ & 35.903 & 50 & 14.097 & \\
\hline $\mathrm{H} 263 / 14$ & 33.662 & 29.338 & -4.324 & 2 \\
\hline $\mathrm{H} 264 / 14$ & 30.979 & 28.426 & -2.553 & 2 \\
\hline $\mathrm{H} 266 / 14$ & 28.532 & 50 & 21.468 & \\
\hline $\mathrm{H} 267 / 14$ & 28.256 & 29.803 & 1.547 & 2 \\
\hline $\mathrm{H} 268 / 14$ & 28.760 & 50 & 21.240 & \\
\hline $\mathrm{H} 269 / 14$ & 28.816 & 31.418 & 2.602 & 2 \\
\hline $\mathrm{H} 270 / 14$ & 29.121 & 50 & 20.879 & \\
\hline $\mathrm{H} 271 / 14$ & 29.730 & 50 & 20.270 & \\
\hline $\mathrm{H} 272 / 14$ & 24.812 & 32.620 & 7.808 & 2 \\
\hline $\mathrm{H} 273 / 14$ & 32.178 & 50 & 17.822 & \\
\hline $\mathrm{H} 274 / 14$ & 29.363 & 36.192 & 6.829 & 1 \\
\hline $\mathrm{H} 275 / 14$ & 25.479 & 26.780 & 1.301 & 2 \\
\hline $\mathrm{H} 276 / 14$ & 26.710 & 50 & 23.290 & \\
\hline
\end{tabular}


Journal of University of Duhok, Vol. 20, No.1 (Pure and Eng. Sciences), Pp 119-141, 2017

DOI: https://doi.org/10.26682/sjuod.2018.20.1.12

\begin{tabular}{ccccc}
\hline $\mathrm{H} 277 / 14$ & 28.669 & 50 & 21.331 & \\
\hline $\mathrm{H} 278 / 14$ & 29.729 & 32.659 & 2.930 & 2 \\
\hline $\mathrm{H} 398 / 14$ & 29.906 & 31.785 & 1.878 & 2 \\
\hline $\mathrm{H} 399 / 14$ & 30.545 & 31.071 & 0.526 & 2 \\
\hline $\mathrm{H} 400 / 14$ & 28.269 & 50 & 21.731 & \\
\hline $\mathrm{H} 403 / 14$ & 27.968 & 35.486 & 7.518 & 2 \\
\hline $\mathrm{H} 404 / 14$ & 28.067 & 28.825 & 0.758 & 2 \\
\hline $\mathrm{H} 406 / 14$ & 26.742 & 31.822 & 5.080 & 2 \\
\hline $\mathrm{H} 407 / 14$ & 29.473 & 30.756 & 1.284 & 2 \\
\hline $\mathrm{H} 409 / 14$ & 26.938 & 33.889 & 6.951 & 2 \\
\hline
\end{tabular}

Table(10): $B R A F$ codon 600 V600E c.1799 T >A PNA Clamp ASLNAqPCR information for cfDNA samples.

\begin{tabular}{|c|c|c|c|c|}
\hline Sample & WT Ct Mean & MUT Ct Mean & $\Delta \mathrm{Ct}$ & Status \\
\hline H347/14 & 29.614 & 50 & 20.386 & \\
\hline $\mathrm{H} 573 / 13$ & 29.614 & 31.523 & 1.909 & 2 \\
\hline $\mathrm{H} 493 / 14$ & 28.532 & 50 & 21.468 & \\
\hline $\mathrm{H} 668 / 13$ & 28.604 & 50 & 21.396 & \\
\hline $\mathrm{H} 631 / 13$ & 29.234 & 32.457 & 3.223 & 2 \\
\hline $\mathrm{H} 327 / 14$ & 28.634 & 50 & 21.366 & \\
\hline H338/14 & 29.691 & 50 & 20.309 & \\
\hline H337/14 & 28.254 & 34.607 & 6.352 & 2 \\
\hline H378/14 & 30.192 & 50 & 19.808 & \\
\hline $\mathrm{H} 1436 / 12$ & 27.953 & 50 & 22.047 & \\
\hline $\mathrm{H} 492 / 13$ & 28.368 & 33.798 & 5.430 & 2 \\
\hline $\mathrm{H} 669 / 13$ & 29.720 & 50 & 20.280 & \\
\hline $\mathrm{H} 1707 / 12$ & 27.362 & 26.208 & -1.154 & 2 \\
\hline H348/14 & 28.915 & 37.299 & 8.384 & 2 \\
\hline H336/14 & 28.916 & 50 & 21.084 & \\
\hline $\mathrm{H} 328 / 14$ & 27.056 & 50 & 22.944 & \\
\hline $\mathrm{H} 346 / 14$ & 29.603 & 50 & 20.397 & \\
\hline $\mathrm{H} 335 / 14$ & 28.329 & 50 & 21.671 & \\
\hline H391/14 & 28.611 & 32.661 & 4.050 & 2 \\
\hline H392/14 & 26.841 & 27.430 & 0.589 & 2 \\
\hline
\end{tabular}

